\title{
Uso da moringa na alimentação animal e humana: Revisão
}

\section{Jéssica Berly Moreira Marinho ${ }^{1 *}$, Alex Martins Varela de Arruda ${ }^{2}$, Raimunda Thyciana Vasconcelos Fernandes ${ }^{3}$, Aurora da Silva Melo ${ }^{3}$, Rosângela Fernandes de Souza ${ }^{1}$, Luiz Odonil Gomes dos Santos ${ }^{4}$, Lívio Carvalho de Figueirêdo ${ }^{2}$, Rogério Taygra Vasconcelos Fernandes $^{3}$, Ana Cecília Nunes de Mesquita ${ }^{1}$}

\author{
${ }^{1}$ Mestrandas em Ciência Animal da Universidade Federal Rural do Semi-Árido \\ ${ }^{2}$ Docentes do Departamento de Ciências Animais, Universidade Federal Rural do Semi-Árido \\ ${ }^{3}$ Doutorandos em Ciência Animal da Universidade Federal Rural do Semi-Árido \\ ${ }^{4}$ Mestrando em Fitotecnia da Universidade Federal Rural do Semi-Árido \\ *Autor para correspondência, E-mail: jessicaberlymm@gmail.com
}

\begin{abstract}
RESUMO. A moringa é uma planta de indiscutível importância econômica na indústria alimentícia e farmacêutica. Suas folhas frescas possuem excelentes qualidades nutricionais, sendo uma boa fonte protéica (33,8\% de proteína bruta), além de conter em sua composição as vitaminas A, B e C, os minerais como, ferro, cálcio, fósforo e potássio e dispor de uma boa digestibilidade (em média 79,7\%), o que a configura como um bom suplemento para animais. É considerada uma fonte valiosa de carotenóides e de compostos bioativos, com atividade hipotensiva e antioxidante. Das sementes pode ser extraído o óleo que apresenta $37,2 \%$ de lipídeos, contendo baixo conteúdo de ácidos graxos poli-insaturados $(<1 \%)$ e desta forma alta resistência à oxidação, pela presença de elevados teores de ácidos graxos insaturados, especialmente o oléico, sendo o palmítico e o bezênico, os ácidos graxos saturados dominantes. O cultivo dessa planta em regiões secas pode ser uma estratégia alimentar bastante vantajosa, uma vez que suas folhas podem ser colhidas quando nenhum outro vegetal verde se apresenta disponível. Desta forma, considerando-se o crescente interesse no uso de alimentos naturais e que forneçam, além de nutrientes, compostos bioativos, apresentamos uma revisão sobre a moringa e suas principais formas de utilização na alimentação animal e humana.
\end{abstract}

Palavras chave: Antioxidantes, ácidos graxos, compostos bioativos, Moringa oleifera

\section{Use of moringa in animal and human nutrition: Review}

\begin{abstract}
Moringa is an indisputable economic importance in plant food and pharmaceutical industry. Its fresh leaves have excellent nutritional value, is a good source of protein (33.8\% crude protein), and contain in its composition vitamin A, B and C, minerals such as iron, calcium, phosphorus and potassium and have good digestibility (average 79.7\%), which configures as a good supplement for animals. It is considered a valuable source of carotenoids and bioactive compounds with hypertensive and antioxidant activity. Seeds can be extracted from the oil which has $37.2 \%$ lipids, containing low content of polyunsaturated fatty acids $(<1 \%)$ and therefore high oxidation resistance, by the presence of high levels of unsaturated fatty acids, especially oleic, and palmitic and bezenic, the dominant saturated fatty acids. The cultivation of this plant in dry are as can be quite advantageous dietary strategy, since its leaves can be harvested when no other vegetable presents available. Thus, considering the growing interest in the use of natural foods and provide, in addition to nutrients, bioactive compounds, present a review of the moringa and its main forms of use for animal and human nutrition.
\end{abstract}

Keywords: antioxidants, bioactive compounds, fatty acids, Moringa oleifera 


\section{Introdução}

A Moringa oleifera é uma planta altamente valorizada, devido a sua composição nutricional, com uma impressionante gama de usos medicinais, sendo utilizadas no combate de avitaminoses A e C, nos tratamentos de reumatismo e gota, como cicatrizantes de feridas, possuem diversos benefícios farmacológicos para o consumo humano, incluindo a promoção do crescimento, efeitos antimicrobianos, terapêuticos e antioxidantes (Makkar \& Becker, 1997, Mbikay, 2012, Moyo et al., 2013). Por essa última propriedade, pode ser também utilizada na prevenção de muitas doenças, como aterosclerose, câncer, reumatismo, dentre outras, que são causadas por radicais livres, podendo ser evitadas por agentes antioxidantes naturais (Mbikay, 2012). Possui diversas aplicações como medicamento alternativos como: anti inflamatório, analgésico, anti asmático, anti anêmico, ativador do metabolismo, purificador, protetor do fígado, hipotensivo, anti espamolítico, produtor de hormônios, promotor de crescimento de pêlo, hidratante, mobilizador de líquidos do corpo (homeostático), desintoxicante, fortalecedor de músculos e ossos, ativador do alerta mental, da memória e da capacidade de aprendizagem (Anwar et al., 2007), inibidor do edema e da atividade diurética (Caceres et al., 1992) e ainda como agente hipocolesterolêmico em pacientes obesos (Ghasi et al., 2000). Além de ser utilizada para produção de biomassa, forragem para animais, agente de limpeza doméstica, fertilizantes, nutriente foliar, goma, suco clarificador de mel e açúcar de cana, biogás, mel, medicina, plantas ornamentais, biopesticida, celulose, purificação da água, entre outros (Fuglie, 1999, Passos et al., 2013). De acordo com Awodele et al. (2012) existem alguns relatos na literatura científica sobre a moringa em relação ao seu poder antibiótico, hipotensor, anti espasmódico, anti úlcera, anti inflamatório, hipocolesterolêmico e atividades de hipoglicemia, além de boa eficiência na purificação de água por floculação, sedimentação e até mesmo na redução de Schistosome cercariae.

\section{Propriedades e características gerais}

A Moringa pertencente à família Moringaceae da ordem Papaverales, cujo único gênero moringa é constituído por quatorze espécies, dentre as quais a Moringa oleifera Lam é a mais conhecida (Anwar et al., 2007). É uma planta nativa do norte da Índia e atualmente é encontrada em vários países dos trópicos e sub trópicos, pois apresenta elevada capacidade de adaptação a condições climáticas e a solos áridos (Lorenzi et al., 2002, Olson \& Fahey, 2011). Conhecida, popularmente por vários nomes comuns: lírio, quiabo de quina ou simplesmente moringa de acordo com os diferentes usos (Ferreira et al., 2008). É considerada uma hortaliça perene arbórea de pequeno porte (Anwar et al., 2007) que obtém cerca de $12 \mathrm{~m}$ de atura, com tronco estreito de no máximo 10 a 30 centímetros de diâmetro e casca de cortiça esbranquiçada, possui uma copa aberta em forma de sombrinha apresentando troca anual de folhas. (Lorenzi et al., 2002). É uma planta alógama, isto é, de fecundação cruzada, que cresce rapidamente de sementes e mudas, igualmente em solos marginais, demandando pouco ou até mesmo nenhum cuidado, por possuir uma resistência que permite viver por longos períodos de estiagem (Gualberto et al., 2015). Pode ser cultivada até 1.400 metros de altitude, em quase todos os tipos de solos, menos naqueles onde há possibilidade de que o terreno fique encharcado (Passos et al., 2013). Suas folhas são bipenadas com sete folíolos pequenos em cada pina (Lalas \& Tsaknis, 2002); e suas flores são agrupadas em inflorescências terminais do tipo cimosa, de coloração amarelo-pálidas, perfumadas, muito procuradas por abelhas e pássaros (Kill et al., 2012) que são os agentes polinizadores de suas flores. Seu fruto é seco do tipo cápsula loculicida, com três valvas de coloração castanho médio (Ramos et al., 2010). As sementes são globóides e aladas, de cor castanho médio, com alas castanho-claro, contendo em seu interior uma massa branca e oleosa (Gualberto et al., 2015) e núcleo é encoberto por uma concha sendo trialadas, oleaginosas e medindo até $1 \mathrm{~cm}$ de diâmetro (Lorenzi et al., 2002). A raiz assemelhase na aparência e no sabor de rabanete, sendo a casca dessa raiz espessa e mole e reticulada, de cor pardo-clara, externamente e branca internamente, lenho mole poroso e amarelo (Caceres et al., 1992).

A Figura 1 mostra a estrutura da planta Moringa oleifera. A: fruto, B: Folhas e C: Flores.

A versatilidade da árvore é notável, possui uma significante importância econômica na indústria e na medicina, pois todas as partes da planta podem ser utilizadas tanto para medicamentos, como para fins industriais, além de serem usadas com alimento, sendo 
consumidas de alguma forma pelo homem e pelos animais. O cultivo dessa planta em regiões secas é muito vantajoso, uma vez que suas folhas podem ser colhidas quando nenhum outro vegetal verde apresenta-se disponível (Olson \& Fahey, 2011), sendo uma excelente alternativa para região nordeste.

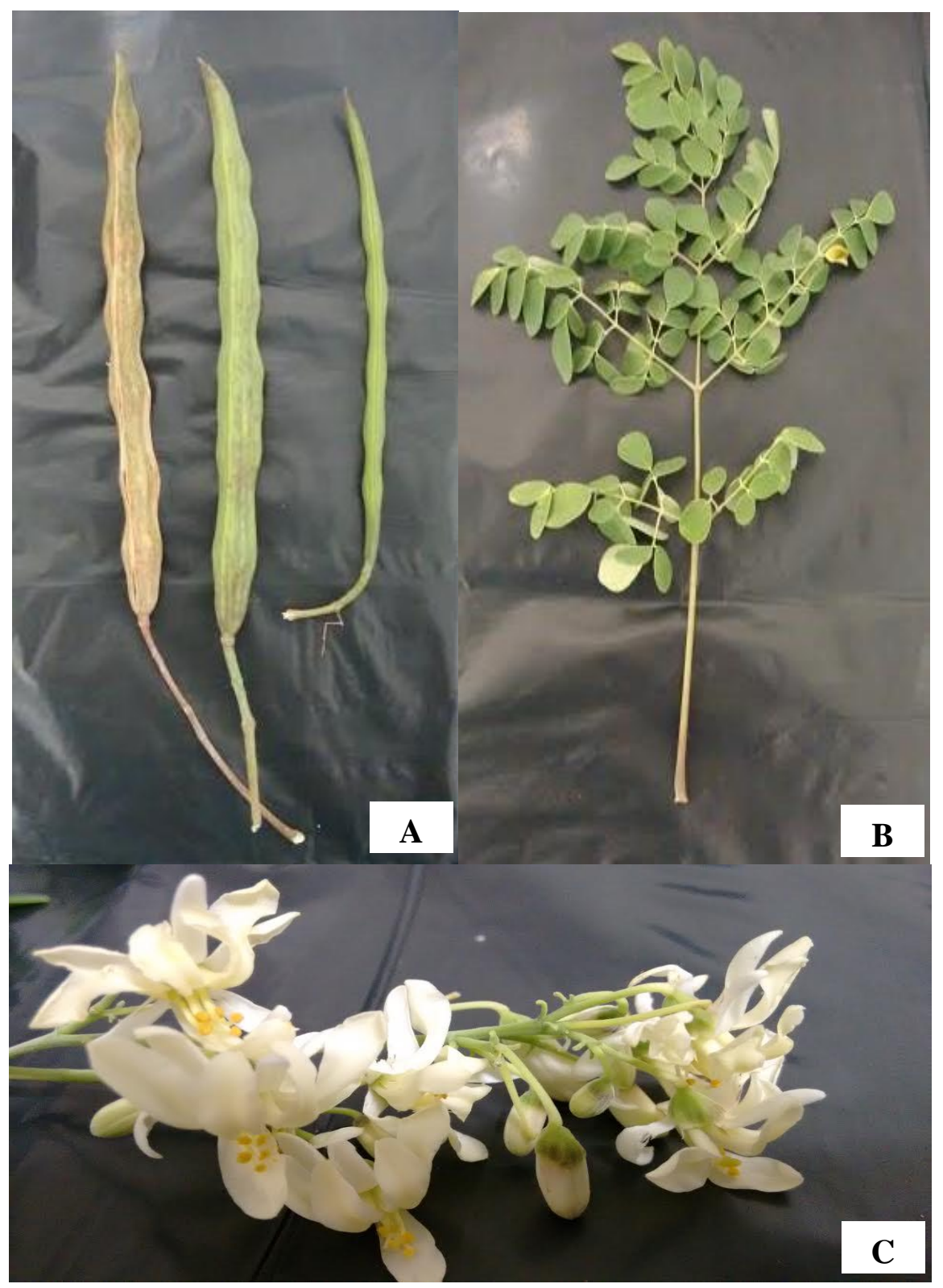

Figura 1. Estrutura da planta Moringa oleifera. A: fruto, B: Folhas e C: Flores.

Perfil nutricional e aplicações na nutrição de aves

As flores emergem em panículas, são de cor creme, perfumadas, muito procuradas pelas abelhas (Gualberto et al., 2015) por possuírem propriedades melíferas que são aproveitadas na apicultura (Passos et al., 2013, Singh et al., 2013) também são comestíveis, e só devem ser consumidas cozidas, fritas na manteiga ou misturadas a outros alimentos (Gualberto et al.,
2015), além de serem utilizadas para fabricação de medicamentos.

As sementes de Moringa oleifera são oleaginosas elas produzem entre $35 \%$ a $40 \%$ (Oliveira et al., 2012) de óleo e podem ser usadas para a produção de biodiesel, o que já ocorre na Îndia. No Brasil, resultados preliminares de análises laboratoriais realizadas pela Petrobrás evidenciam a potencialidade da planta como uma alternativa importante para a produção de 
biodiesel. Das sementes pode ser extraído o óleo que apresenta $37,2 \%$ de lipídeos, contendo baixo conteúdo de ácidos graxos poliinsaturados $(<1 \%)$ e desta forma alta resistência à oxidação, pela presença de elevados teores de ácidos graxos insaturados, especialmente o oléico, sendo o palmítico e o bezênico, os ácidos graxos saturados dominantes (Lalas \& Tsaknis, 2002, Passos et al., 2013) e podem ser utilizados na alimentação, indústria de biodiesel, cosméticos e de fármacos (Lalas \& Tsaknis, 2002). E por apresentarem aproximadamente $33,9 \%$ de proteínas (Bezerra et al., 2004) podem ser utilizadas como substitutos protéicos, na aplicação farmacológica como anti inflamatórios, anti microbianos e no tratamento de água por possuir propriedade coagulante/floculante (Vieira et al., 2010). Estudos recentes mostraram a atividade antifúngica de extratos e óleo essencial de $M$. oleifera, frente a diversas espécies fúngicas, levantando o interesse da comunidade científica (Chuang et al., 2007).

As folhas ou partes delas são uma fonte de alimento bastante promissor, principalmente para os trópicos, porque essas árvores possuem folhas durante todo o período de estiagem (Fahey, 2005). As folhas frescas de Moringa têm excelentes qualidades nutricionais, sendo uma boa fonte protéica com $33,8 \%$ de proteínas (Gallão et al., 2008), possuindo em sua composição vitaminas $\mathrm{A}, \mathrm{B}, \mathrm{C}$, minerais como: ferro, cálcio, fósforo, potássio e zinco (Moyo et al., 2013) possuindo uma digestibilidade in vitro de $79,7 \%$, sendo considerado um excelente suplemento para animais (Sánchez et al., 2006). Segundo Goméz \& K.J.O. (2014) as folhas da moringa fornecem mais vitamina A do que cenouras, mais vitamina $\mathrm{C}$ do que laranjas, mais cálcio do que o leite, mais potássio do que a banana, mais ferro do que o espinafre e mais proteína do que qualquer outro vegetal. Além de ser considerada uma fonte valiosa de carotenóides e de compostos bioativos, com atividade hipotensiva e antioxidante (Ferreira et al., 2008). Por essa última propriedade, Chumark et al. (2008) e Talreja (2010) comprovaram em suas pesquisas o poder antioxidante in vivo e in vitro da folha da moringa, assim como a prevenção da aterosclerose, redução do colesterol e o alto potencial terapêutico para a prevenção de doenças cardiovasculares. Com relação a quantidade de aminoácidos Segundo Makkar \& Becker (1997) o perfil de M. oleifera folhas secas mostrou níveis elevados de aminoácidos importantes na produtividade de aves caipiras. Dez dos 19 aminoácidos observados em M. oleifera são categorizados como essenciais; são eles: treonina, tirosina, metionina, valina, fenilalanina, isoleucina, leucina, histidina, lisina e triptofano. Além disso, segundo as pesquisas de Makkar \& Becker (1997) as folhas da moringa não contém fatores anti nutricionais como: taninos, lecitinas ou inibidores de tripsina.

Diante disso, a moringa vem sendo amplamente estudada e utilizada para o consumo humano; porém pouco se sabe sobre a utilização e os benefícios da mesma na alimentação animal. Por isso, pesquisas estão sendo realizadas em vários países com o objetivo de avaliar a inclusão da moringa na alimentação de aves. Segundo Nkukwana et al. (2014), a inclusão das folhas de Moringa olifera na dieta de aves como promotor de desempenho, apresentaram efeitos benéficos na melhoria da eficiência alimentar na fase de crescimento das aves, sugerindo que futuras pesquisas, contenham níveis maiores do $2,5 \%$ de inclusão dietética para determinar digestão e retenção de nutrientes, o que ajudaria a elucidar o efeito dos compostos bioativos nas folhas sobre desempenho. De acordo com o trabalho de Donkor et al. (2013), ao avaliarem a utilização das folhas de Moringa olifera na dieta das aves e os potenciais minerais dessa planta. Esses autores observaram que a inclusão das folhas da moringa na dieta das aves aumentou o ganho de peso e outras características gerais dos frangos de corte, como: bico e pernas brilhantes. Além da ausência de metais pesados nas folhas, tornando assim a sua incorporação em alimentos seguros para aves. Corroborando com esses resultados satisfatórios, o estudo desenvolvido por Melesse et al. (2009) demonstraram que a suplementação das folhas de moringa na dieta de pintos pode ser considerada uma estratégia para a alimentação alternativa em práticas de produção de frangos rurais em regiões tropicais.

\section{Compostos bioativos}

Nos alimentos vegetais são encontrados compostos considerados não nutrientes, também conhecidos como compostos bioativos, que apresentam diversos benefícios à saúde. Esses compostos são considerados potentes antioxidantes que possuem a importante função de neutralizar os radicais livres no organismo humano, reduzindo assim o risco de doenças tais como artrite, doenças cardiovasculares, câncer, além de retardar o processo de envelhecimento 
(Faustino et al., 2007), possuem atividades biológicas como antioxidantes, anti inflamatória e hipocolesterolêmica (Carratu \& Sanzini, 2005). Normalmente esses compostos bioativos são originados do metabolismo secundário das plantas. Esses metabólicos secundários que são produzidos a partir do metabolismo auxiliam as plantas a aumentarem a capacidade de sobrevivência e superação dos desafios locais, proporcionando a interação com meio exterior. Portanto, os compostos bioativos nas plantas são definidos como metabólitos secundários que provocam efeitos farmacológicos ou toxicológicos em humanos e animais (Azmir et al., 2013). Contudo, é de suma importância a identificação das características físico-químicas e a quantificação dessas substâncias bioativas na planta, pois são de grande interesse para acrescentar qualidade nutricional e agregar valor ao produto final (Souza et al., 2012, Martins et al., 2011). Dentre esses compostos bioativos estão: os carotenóides, flavonóides, polifenóis, dentre outros.

\section{Carotenóides}

Os carotenóides são um grupo de pigmentos naturais presentes em frutos e produtos hortícolas responsáveis pelas cores, amarelo, laranja e vermelho (Habib et al., 2013). Esses carotenóides presentes nos vegetais por sua vez também possuem funções antioxidantes, prevenindo deficiências de vitamina A e quando consumido com lipídios, apresentam uma maior biodisponibilidade (Andarwulan et al., 2012). Em termos nutricionais alguns carotenóides são fonte de vitamina A (Cooper, 2004). Entre eles, está o $\beta$-caroteno com a maior atividade de provitamina A, pois estruturalmente sua molécula corresponde a duas moléculas de retinol (vitamina A). Os carotenóides possuem também atividades antioxidantes, devido sua interação com radicais livres, agindo assim na prevenção de doenças cancerígenas até doenças cardiovasculares (Grune et al., 2010). Os vegetais folhosos ou não folhosos de modo geral estudados por Kunyanga et al. (2012) apresentaram um perfil qualitativo quanto aos teores de carotenóides, tais como a luteína, o $\beta$ caroteno, a violaxantina e a neoxantina os principais. De acordo com Andarwulan et al. (2012) os teores de carotenóides totais mais elevados, foram em torno de $13,96 \mathrm{mg}$ de $\beta$ caroteno por $100 \mathrm{~g}$. Segundo as pesquisas realizadas por Lako et al. (2007) os teores de $\beta$ - caroteno observados nas folhas de Moringa oleifera cozida a vapor foram de $340 \mu \mathrm{g}$ por grama e para folhas ferventadas e de $280 \mu \mathrm{g}$ por grama.

\section{Vitamina c}

A vitamina $\mathrm{C}$ também conhecida como ácido ascórbico é um composto cristalino, que apresenta sabor ácido e é encontrada em frutas cítricas, além disso, é também classificada como uma vitamina hidrossolúvel. Tem grande importância para o organismo, pois desempenha diversas funções Entre as principais pode-se citar a de antioxidante, atuando também cofator para a biossíntese do colágeno, cartinina, hormônios peptídicos e neurotransmissores (Carr et al., 2013). As principais fontes de ácido ascórbico encontram-se nas frutas e vegetais destacando-se a laranja, a tangerina, o limão, a acerola, a cereja, o melão e o abacaxi. Entre os vegetais, destacamse o tomate, a couve, o pimentão e os brócolis. E outro vegetal que tem sido bastante estudado é tem se destacado pelo teor de vitamina $\mathrm{C}$ é a Moringa oleifera. Segundo a literatura, o teor de vitamina $\mathrm{C}$ para folha de Moringa de acordo com a tabela de composição de alimento é de, $164 \mathrm{mg}$ AA por $100 \mathrm{~g}$ folha fresca (Kunyanga et al., 2012).

\section{Flavonóides}

Os flavonóides pertencem a uma classe de compostos amplamente distribuída no reino vegetal e representam uma das classes de metabólitos secundários mais importantes e diversificadas entre os produtos naturais. Encontra-se em abundância nas angiospermas e têm grande diversidade estrutural. Nas plantas, os flavonóides estão envolvidos em uma variedade de processos biológicos e possuem diversas atividades, como: a de antioxidante; controlam a ação de hormônios vegetais e inibem enzimas.

\section{Antocianinas}

As antocianinas são compostos pertencentes ao grupo dos flavonóides e constituem grupos de pigmentos responsáveis por grande parte das cores em flores, frutas, folhas, caules e raízes de plantas (Teixeira et al., 2015).

\section{Polifenóis}

Os polifenóis constituem um grupo heterogêneo, composto de várias classes de substâncias com propriedade antioxidante, 
encontrados em plantas, frutas, sucos e vinhos. São compostos naturais e biologicamente importantes, uma vez que possuem não só atividades farmacológicas e biológicas como também influenciam a qualidade sensorial dos alimentos de origem vegetal. São agentes redutores e em conjunto com outras substâncias redutoras, como a vitamina $\mathrm{C}$, vitamina $\mathrm{E}$ e os carotenóides, podem proteger os tecidos contra o estresse oxidativo, sendo comumente mencionados como antioxidantes (Prior \& Guohua, 2000). Segundo Lako et al. (2007), as folhas da moringa possuem atividade antioxidante e são ricas em polifenóis totais, quercetina, campferol e $\beta$ caroteno.

\section{Taninos}

Os taninos são componentes polifenoicos encontrados em plantas, alimentos e bebidas (Pansera et al., 2003). Estão presentes na fração de fibra alimentar de diferentes alimentos e podem ser considerados indigeríveis ou pouco digeríveis (Bartolomé et al., 1995). Apesar da ação negativa do tanino no valor nutritivo de certos vegetais, em particular a redução de digestibilidade de proteínas, a inibição da ação de enzimas digestivas e interferência na absorção de ferro, os efeitos do tanino na saúde humana ainda são questionáveis devido à limitação de estudos nesta área. Apresentam habilidade para interagir e precipitar proteínas e parecem ser responsáveis pela adstringência de muitas plantas. Em folhas de Moringa oleifera foi verificada por Ferreira et al. (2008) baixa quantidade de taninos (12 mg por g/MS) e ausência dos compostos cianogênicos.

\section{Fibra}

As fibras possuem várias características como: solubilidade, viscosidade, formação de gel, capacidade de retenção de água e aumento de volume devido a associação entre moléculas (Cummings \& Stephen, 2007, Mudgil \& Barak, 2013). Dentre essas propriedades a solubilidade é uma das mais importantes e é a partir dessa característica que podemos classificar os carboidratos não digeríveis em solúveis e insolúveis.

As fibras solúveis são fermentáveis, viscosas e gelificantes o que lhes confere uma série de benefícios fisiológicos, tais como: retardamento do esvaziamento gástrico e do tempo de trânsito no intestino delgado (Baik \& Ullrich, 2008, Mira et al., 2009), modulação da motilidade gastrintestinal, aumento da massa, volume e consistência das fezes, aumento na absorção de água, adsorção de ácidos biliares. Pertencem a esse grupo: as substâncias pécticas, gomas, mucilagens, alginatos, $\beta$-glucanas (Elleuch et al., 2011).

As fibras insolúveis são conhecidas como fibras que não se solubilizam em água. Encontradas em alimentos de origem vegetal pelo fato da parede celular conter fibras não digeríveis no trato gastrointestinal humano. Estão presentes nesse grupo: celulose, hemicelulose, lignina e amido resistente (Elleuch et al., 2011, Mudgil \& Barak, 2013). Essas fibras se caracterizam por serem pouco fermentáveis e não viscosas, pela sua a capacidade de reter água, aumentar a massa fecal, estimular o peristaltismo, provocando consequentemente o aumento da velocidade de passagem da digesta e da motilidade, diminuindo a constipação, e a absorção de nutrientes (Mira et al., 2009, Mann \& Cummings, 2009, Elleuch et al., 2011).

\section{Clorofila}

As clorofilas são pigmentos geralmente encontrados em folhas, frutos e outros alimentos de origem vegetal, são responsáveis pelas colorações amarela, laranja e vermelha, sendo que nos vegetais folhosos apresentam coloração verde intensa, devido a suas fortes absorções das regiões azuis e vermelhas do espectro eletromagnético e por causa destas absorções, a luz que ela reflete e transmite parece verde ( $\underline{\text { Streit }}$ et al., 2005). A clorofila a, é a mais abundante e a mais importante das clorofilas, corresponde a aproximadamente $75 \%$ dos pigmentos verdes encontrados nos vegetais (Gross, 2012). Frequentemente utilizada como um indicador do crescimento de algas e cianobactérias devido principalmente ao enriquecimento por nutrientes, como o nitrogênio e fósforo, processo este denominado de eutrofização (APHA, 2014).

\section{Perspectivas futuras}

É esperado que nos próximos anos mais pesquisas que fomentem o uso da moringa na alimentação animal e humana sejam desenvolvidas, uma vez que o uso de alimentos naturais, que além de nutrir possuam compostos bioativos, pode ser não apenas viável, mas possibilitar melhores resultados de desempenho e digestibilidade em animais e efeitos benéficos no organismo humano. 


\section{Referências Bibliográficas}

Andarwulan, N., Kurniasih, D., Apriady, R. A., Rahmat, H., Roto, A. V. \& Bolling, B. W. (2012). Polyphenols, carotenoids, and ascorbic acid in underutilized medicinal vegetables. Journal of Functional Foods, 4, 339-347.

Anwar, F., Latif, S., Ashraf, M. \& Gilani, A. H. (2007). Moringa oleifera: a food plant with multiple medicinal uses. Phytotherapy Research, 21, 17-25.

APHA. (2014). Standard methods for the examination of water and wastewater. American Public Health Association.

Awodele, O., Oreagba, I. A., Odoma, S., Silva, J. A. T. \& Osunkalu, V. O. (2012). Toxicological evaluation of the aqueous leaf extract of Moringa oleifera Lam. (Moringaceae). Journal of Ethnopharmacology, 139, 330-336.

Azmir, J., Zaidul, I. S. M., Rahman, M. M., Sharif, K. M., Mohamed, A., Sahena, F., Jahurul, M. H. A., Ghafoor, K., Norulaini, N. A. N. \& Omar, A. K. M. (2013). Techniques for extraction of bioactive compounds from plant materials: a review. Journal of Food Engineering, 117, 426-436.

Baik, B.-K. \& Ullrich, S. E. (2008). Barley for food: characteristics, improvement, and renewed interest. Journal of Cereal Science, $48,233-242$.

Bartolomé, B., Jiménez-Ramsey, L. M. \& Butler, L. G. (1995). Nature of the condensed tannins present in the dietary fibre fractions in foods. Food Chemistry, 53, 357-362.

Bezerra, A. M. E., Medeiros Filho, S., Freitas, J. B. S. \& Teófilo, E. M. (2004). Avaliação da qualidade das sementes de Moringa oleifera Lam. durante o armazenamento. Ciência $e$ Agrotecnologia, 28, 1240-1246.

Caceres, A., Saravia, A., Rizzo, S., Zabala, L., De Leon, E. \& Nave, F. (1992). Pharmacologie properties of Moringa oleifera. 2: Screening for antispasmodic, antiinflammatory and diuretic activity. Journal of Ethnopharmacology, 36, 233-237.

Carr, A. C., Bozonet, S. M., Pullar, J. M., Simcock, J. W. \& Vissers, M. C. M. (2013). Human skeletal muscle ascorbate is highly responsive to changes in vitamin $\mathrm{C}$ intake and plasma concentrations. The American Journal of Clinical Nutrition, 97, 800-807.

Carratu, B. \& Sanzini, E. (2005). Sostanze biologicamente attive presenti negli alimenti di origine vegetale. Ann Ist Super Sanita, 41, 7-16.

Chuang, P.-H., Lee, C.-W., Chou, J.-Y., Murugan, M., Shieh, B.-J. \& Chen, H.-M. (2007). Anti-fungal activity of crude extracts and essential oil of Moringa oleifera Lam. Bioresource Technology, 98, 232-236.

Chumark, P., Khunawat, P., Sanvarinda, Y., Phornchirasilp, S., Morales, N. P., Phivthongngam, L., Ratanachamnong, P., Srisawat, S. \& Klai-upsorn, S. P. (2008). The in vitro and ex vivo antioxidant properties, hypolipidaemic and antiatherosclerotic activities of water extract of Moringa oleifera Lam. leaves. Journal of Ethnopharmacology, 116, 439-446.

Cooper, D. A. (2004). Carotenoids in health and disease: recent scientific evaluations, research recommendations and the consumer. The Journal of Nutrition, 134, 221S-224S.

Cummings, J. H. \& Stephen, A. M. (2007). Carbohydrate terminology and classification. European Journal of Clinical Nutrition, 61, S5-S18.

Donkor, A.-M., Glover, R. L. K., Addae, D. \& Kubi, K. A. (2013). Estimating the nutritional value of the leaves of Moringa oleifera on poultry. Food and Nutrition Sciences, 4, 1077-1083.

Elleuch, M., Bedigian, D., Roiseux, O., Besbes, S., Blecker, C. \& Attia, H. (2011). Dietary fibre and fibre-rich by-products of food processing: Characterisation, technological functionality and commercial applications: A review. Food Chemistry, 124, 411-421.

Fahey, J. W. (2005). Moringa oleifera: A Review of the medical evidence for its nutritional, therapeutic, and prophylactic properties. Part 1. Trees for Life Journal, 1, 1-24.

Faustino, J. M. F., Barroca, M. J. \& Guiné, R. P. F. (2007). Study of the drying kinetics of green bell pepper and chemical characterization. Food and Bioproducts Processing, 85, 163-170.

Ferreira, P. M. P., Farias, D. F., Oliveira, J. \& Carvalho, A. F. U. (2008). Moringa oleifera: 
compostos bioativos e potencialidade nutricional. Revista de Nutrição, 21, 431-437.

Fuglie, L. J. (1999). The miracle tree: Moringa oleifera: natural nutrition for the tropics.

Gallão, M. I., Damasceno, L. F. \& Brito, E. S. (2008). Avaliação química e estrutural da semente de moringa. Revista Ciência Agronômica, 37, 106-109.

Ghasi, S., Nwobodo, E. \& Ofili, J. (2000). Hypocholesterolemic effects of crude extract of leaf of Moringa oleifera Lam in high-fat diet fed Wistar rats. Journal of Ethnopharmacology, 69, 21-25.

Goméz, A. V. \& K.J.O., A. (2014). Revisión de las características y usos de la planta Moringa oleífera. Investigación \& Desarrollo, 22, 110.

Gross, J. (2012). Pigments in vegetables: chlorophylls and carotenoids. Springer Science \& Business Media.

Grune, T., Lietz, G., Palou, A., Ross, A. C., Stahl, W., Tang, G., Thurnham, D., Yin, S. A. \& Biesalski, H. K. (2010). $\beta$-carotene is an important vitamin A source for humans. Journal of Nutrition, 140, 2268S-2285S.

Gualberto, A. F., Ferrari, G. M., Abreu, K. M. P., Lima Preto, B. \& Ferrari, J. L. (2015). Características, propriedades e potencialidades da moringa (Moringa oleifera Lam.): Aspectos agroecológicos. Revista Verde de Agroecologia e Desenvolvimento Sustentável, 9, 19-25.

Habib, H. M., Kamal, H., Ibrahim, W. H. \& Dhaheri, A. S. A. (2013). Carotenoids, fat soluble vitamins and fatty acid profiles of 18 varieties of date seed oil. Industrial Crops and Products, 42, 567-572.

Kill, L. H. P., Martins, C. T. V. D. \& Lima, P. C. F. (2012). Moringa oleifera: Registro dos visitantes florais e potencial apícola para a região de Petrolina, PE. Boletim de Pesquisa e Desenvolvimento, 1, 1-19.

Kunyanga, C. N., Imungi, J. K., Okoth, M. W., Biesalski, H. K. \& Vadivel, V. (2012). Total phenolic content, antioxidant and antidiabetic properties of methanolic extract of raw and traditionally processed Kenyan indigenous food ingredients. Food Science and Technology, 45, 269-276.
Lako, J., Trenerry, V. C., Wahlqvist, M., Wattanapenpaiboon, N., Sotheeswaran, S. \& Premier, R. (2007). Phytochemical flavonols, carotenoids and the antioxidant properties of a wide selection of Fijian fruit, vegetables and other readily available foods. Food Chemistry, 101, 1727-1741.

Lalas, S. \& Tsaknis, J. (2002). Characterization of Moringa oleifera seed oil variety "Periyakulam 1". Journal of Food Composition and Analysis, 15, 65-77.

Lorenzi, H., Matos, F. J. \& Francisco, J. M. (2002). Plantas medicinais no Brasil: nativas e exóticas.

Makkar, H. P. S. \& Becker, K. (1997). Nutrients and antiquality factors in different morphological parts of the Moringa oleifera tree. The Journal of Agricultural Science, 128, 311-322.

Mann, J. I. \& Cummings, J. H. (2009). Possible implications for health of the different definitions of dietary fibre. Nutrition, Metabolism and Cardiovascular Diseases, 19, 226-229.

Martins, S., Mussatto, S., Martínez-Avila, G., Montañez-Saenz, J., Aguilar, C. N. \& Teixeira, J. A. (2011). Bioactive phenolic compounds: production and extraction by solid-state fermentation. A review. Biotechnology Advances, 29, 365-373.

Mbikay, M. (2012). Therapeutic potential of Moringa oleifera leaves in chronic hyperglycemia and dyslipidemia: a review. Frontiers in Pharmacology, 3, 1-12.

Melesse, A., Bulang, M. \& Kluth, H. (2009). Evaluating the nutritive values and in vitro degradability characteristics of leaves, seeds and seedpods from Moringa stenopetala. Journal of the Science of Food and Agriculture, 89, 281-287.

Mira, G. S., Graf, H. \& Cândido, L. M. B. (2009). Visão retrospectiva em fibras alimentares com ênfase em beta-glucanas no tratamento do diabetes. Brazilian Journal of Pharmaceutical Sciences, 45, 11-20.

Moyo, B., Masika, P. J., Hugo, A. \& Muchenje, V. (2013). Nutritional characterization of Moringa (Moringa oleifera Lam.) leaves. African Journal of Biotechnology, 10, 1292512933. 
Mudgil, D. \& Barak, S. (2013). Composition, properties and health benefits of indigestible carbohydrate polymers as dietary fiber: A review. International Journal of Biological Macromolecules, 61, 1-6.

Nkukwana, T. T., Muchenje, V., Masika, P. J., Hoffman, L. C., Dzama, K. \& Descalzo, A. M. (2014). Fatty acid composition and oxidative stability of breast meat from broiler chickens supplemented with Moringa oleifera leaf meal over a period of refrigeration. Food Chemistry, 142, 255-261.

Oliveira, D. S., Xavier, D. S. F., Farias, P. N., Bezerra, V. S., Pinto, C. H. C., Souza, L., Santos, A. G. D. \& Oiveira, L. G. M. (2012). Obtenção do biodiesel através da transesterificação do óleo de Moringa Oleífera Lam. Holos, 1, 49-61.

Olson, M. E. \& Fahey, J. W. (2011). Moringa oleifera: un árbol multiusos para las zonas tropicales secas. Revista Mexicana de Biodiversidad, 82, 1071-1082.

Pansera, M. R., Santos, A. C., Paese, K., Wasum, R., Rossato, M., Rota, L. D., Pauletti, G. F. \& Serafini, L. A. (2003). Análise de taninos totais em plantas aromáticas e medicinais cultivadas no Nordeste do Rio Grande do Sul. Revista Brasileira de Farmacognosia, 13, 1722.

Passos, M., Santos, D. M. C., Santos, B. S., Souza, D. C. L., Santos, J. A. B. \& Silva, G. F. (2013). Qualidade pós-colheita da moringa (Moringa oleifera lam) utilizada na forma in natura e seca. GEINTEC-Gestão, Inovação e Tecnologias, 3, 113-120.

Prior, R. L. \& Guohua, C. (2000). Antioxidant phytochemicals in fruits and vegetables: Diet and health implications: The Role of Oxidative Stress and Antioxidants in Plant and Human Health. HortScience, 35, 588-592.

Ramos, L. M., Costa, R. S., Môro, F. V. \& Silva, R. C. (2010). Morfologia de frutos e sementes e morfofunção de plântulas de Moringa (Moringa oleifera Lam.). Comunicata Scientiae, 1, 156-160.

Sánchez, N. R., Spörndly, E. \& Ledin, I. (2006). Effect of feeding different levels of foliage of Moringa oleifera to creole dairy cows on intake, digestibility, milk production and composition. Livestock Science, 101, 24-31.
Singh, R. S. G., Negi, P. S. \& Radha, C. (2013). Phenolic composition, antioxidant and antimicrobial activities of free and bound phenolic extracts of Moringa oleifera seed flour. Journal of Functional Foods, 5, 18831891.

Souza, V. R., Pereira, P. A. P., Queiroz, F., Borges, S. V. \& Carneiro, J. D. S. (2012). Determination of bioactive compounds, antioxidant activity and chemical composition of Cerrado Brazilian fruits. Food Chemistry, 134, 381-386.

Streit, N. M., Canterle, L. P., Canto, M. W. d. \& Hecktheuer, L. H. H. (2005). The chlorophylls. Ciência Rural, 35, 748-755.

Talreja, T. (2010). Screening of crude extract of flavonoids of Moringa oleifera against bacteria and fungal pathogen. Journal of Phytology, 2, 31-35.

Teixeira, L. N., Stringheta, P. C. \& Oliveira, F. A. (2015). Comparação de métodos para quantificação de antocianinas. Revista Ceres, 55, 297-304.

Vieira, A. M. S., Vieira, M. F., Silva, G. F., Araújo, Á. A., Fagundes-Klen, M. R., Veit, M. T. \& Bergamasco, R. (2010). Use of Moringa oleifera seed as a natural adsorbent for wastewater treatment. Water, Air, and Soil Pollution, 206, 273-281.

\section{Article History:}

Received 21 April, 2016

Accepted 17 May, 2016

Available online 7 June, 2016

License information: This is an open-access article distributed under the terms of the Creative Commons Attribution License, which permits unrestricted use, distribution, and reproduction in any medium, provided the original work is properly cited 